\title{
A criança com Transtorno do Espectro Autista, a escola e o professor: algumas reflexões
}

\author{
Hélen Bandeira Rosso Matias \\ Centro Universitário Leonardo da Vinci - UNIASSELVI, Brasil \\ Melissa Probst \\ Instituto Federal Catarinense - IFC/campus Araquari, Brasil
}

\begin{abstract}
RESUMO
O presente estudo propõe uma reflexão sobre o transtorno do espectro autista (TEA), a criança, a escola e a ação e importância da ação docente. Objetivou-se, entre outros aspectos, refletir sobre os processos educativos e particularidades das crianças com Transtorno do Espectro Autista. Para a realização do estudo, do qual o presente texto é resultante, optou-se pela pesquisa qualitativa, de revisão bibliográfica. Partindo do pressuposto de que o Transtorno do Espectro Autista (TEA) ainda é um tanto quanto desconhecido, no contexto social e educacional, justifica-se a discussão da questão. Conclui-se que conhecer a criança e o seu mundo particular pode tornar esse processo inclusivo, de aceitação como um processo duradouro, que poderá servir de amparo à criança, ao professor e à família, lembrando que o acesso à escola é um direito de todos.
\end{abstract}

PALAVRAS-CHAVE: Criança. Transtorno do Espectro Autista. Educação inclusiva.

\section{THE CHILD WITH AUTISTIC SPECTRUM DISORDER, SCHOOL AND TEACHER: SOME REFLECTIONS}

\begin{abstract}
The present study proposes a reflection about the autism spectrum disorder (ASD), the child, the school and the action and importance of the teaching action. The objective was, among other aspects, to reflect on the educational processes and particularities of children with Autism Spectrum Disorder. For the accomplishment of the study, of which the present text is the result, we opted for the qualitative research, of bibliographical revision. Based on the assumption that Autism Spectrum Disorder (ASD) is still somewhat unknown, in the social and educational context, it is justified to discuss the issue. It is concluded that knowing the child and his / her particular world can make this process inclusive, accepting as a lasting process, that can serve as a shelter to the child, the teacher and the family, remembering that access to school is a right of all.
\end{abstract}

KEYWORDS: Child. Autism Spectrum Disorder. Inclusive education. 


\section{EL NIÑO CON TRANSTORNO DEL ESPECTRO AUTISTA, LA ESCUELA Y EL PROFESOR: ALGUNAS REFLEXIONES}

\section{RESUMEN}

El presente estudio propone una reflexión sobre el trastorno del espectro autista (TEA), el niño, la escuela y la acción y la importancia de la acción docente. El objetivo fue, entre otros aspectos, a reflejarse en los procesos educativos y las particularidades de los niños con Autism Spectrum desorden. Para el logro del estudio, del que el texto actual es el resultado, hemos optado por la investigación cualitativa, de la bibliografía revisada. Basado en el signo que el Autism Spectrum Disorder (ASD) sigue siendo todavía desconocido, en el contexto niño y el suyo personal del mundo pueden hacer este proceso incluso, aceptando a un processo de suspensión, que puede servir a la familia para el niño, el profesor y la familia, que recuerdan que el acceso a la escuela es um derecho de todos.

PALABRAS CLAVE: Niño. Desorden del Espectro Autista. Educación inclusiva.

\section{INTRODUÇÃO}

O Transtorno do Espectro Autista (TEA) ainda é um tanto quanto desconhecido, no contexto social. Pesquisadores da ciência vêm dedicando tempo de estudos sobre transtorno sem ainda ter encontrado definições a respeito de suas causas, tratamento ou cura. Além disso, são muitas bibliografias que tratam o assunto apenas na superficialidade, deixando assim os interessados na questão com a falsa ilusão de compreensão da situação.

Sabe quando a gente vai arrumar o armário e a bagunça chega a um ponto em que fica pior do que quando começamos? Agora, estamos neste ponto na história do Autismo. De algum modo, nosso conhecimento sobre ele aumentou muito desde a década de 1940. Mas, por outro lado estamos tão confusos como antes. Por sorte, acho que estamos prontos para avançar do ponto de confusão máxima (GRANDIN; PANEK, 2015, p. 27).

Buscar conhecimentos mais específicos e não apenas nos cercarmos de conceitos fechados e rótulos faz-se essencial para discutir a questão. Tamanha a complexidade da questão, metaforicamente podemos dizer que a criança com TEA poderia ser comparada às "digitais" de um ser humano, pois não haverá outra criança que apresente os sintomas e característica exatamente iguais. Dada essa diferença, tem-se como nomenclatura o termo "espectro". Conhecer mais sobre a criança com o Transtorno do Espectro Autista é, na atualidade, um desafio que se põe à sociedade que se diz inclusiva, apoiadora da diversidade. Desse modo, conhecer a criança e o seu mundo particular pode tornar esse processo inclusivo, de aceitação como um processo duradouro, que poderá servir de amparo à criança e a família nesta nova jornada. 
A pergunta que impulsionou o presente estudo foi: "existem necessidades e particularidades de uma criança com Transtorno do Espectro Autista (TEA)?” A partir de tal questionamento, o estudo teve, como objetivo geral, a intenção de refletir sobre os processos educativos e particularidades das crianças com Transtorno do Espectro Autista. Além deste, outros objetivos foram elencados, tais como conhecer os fatos históricos relevantes à identificação e inclusão da criança com TEA, bem como analisar e refletir sobre os sintomas e características do TEA.

Considerando esse estudo como uma reflexão a respeito de conhecimentos já produzidos, sem que haja a previsão de aplicabilidade imediata, ele se configura como uma pesquisa de natureza básica, descritiva de abordagem qualitativa, que teve como procedimento técnico a revisão bibliográfica.

\section{O TRANSTORNO DO ESPECTRO AUTISTA (TEA)}

O autismo vem recebendo, nos últimos tempos, muita atenção por parte dos estudiosos, e a partir de diferentes campos do conhecimento: medicina, psicologia e educação. Percebe-se que de modo geral vem se buscando uma melhor compreensão a respeito do tema, para discutir novas metodologias e práticas de atendimento ao autista.

A respeito da definição do termo, de acordo com Gomes (2007), a palavra autismo remete a uma união de duas palavras: "autos" que significa "em si mesmo" e "ismo" que significa "voltado para". Nesse sentido, portanto, o termo autismo significa "voltado a si mesmo". A partir disso, tem-se que o autismo não é uma "deficiência”, mas sim um transtorno, ou seja, uma alteração no desenvolvimento dos indivíduos.

Historicamente podemos apontar para Kanner (apud BRASIL, 2013) como um dos principais estudiosos sobre o assunto, visto que ele, ao descrever o transtorno, apresentou algumas das principais características do transtorno:

Incapacidade inata de estabelecer o contato afetivo habitual e biologicamente previsto com as pessoas, exatamente como as outras crianças veem ao mundo com deficiências físicas ou intelectuais, mas também sugeriu que os problemas dos filhos teriam alguma articulação com a personalidade dos pais e o tipo de relações precoces estabelecidas entre eles e a criança (KANNER apud BRASIL, 2013, p. 19).

Na décima revisão da Classificação Internacional de Doenças - CID 10 o autismo é considerado um transtorno do desenvolvimento. Sobre o assunto, Tamanaha, Perissinoto e Chiari (2008, p. 4) afirmam que 
[...] os Transtornos Globais do Desenvolvimento foram classificados como um grupo de alterações, caracterizadas por alterações qualitativas da interação social e modalidades de comunicação, e por um repertório de interesses e atividades restrito e estereotipado. Essas anomalias qualitativas constituem uma característica global do funcionamento do indivíduo.

As pessoas que tem o Transtorno do Espectro Autista podem apresentar alguns sintomas entre os 12 e os 24 meses de vida, com uma variante de gravidade e intensidade, dependendo da criança. Vale registrar que as circunstâncias desses sintomas não são considerados fatores determinantes para o diagnóstico de autismo, para isso há um procedimentos específicos que podem ser caracterizados como complexos. Para que o diagnóstico seja dado, é necessário o acompanhamento com profissionais da saúde, bem como relatórios sobre o desenvolvimento da criança e seu comportamento no contexto escolar.

A inclusão da síndrome de Asperger no DSW-IV em 1994 validou a ideia de um espectro autista, mas o significado de "espectro" mudou ao longo do tempo. "Nos círculos científicos", um artigo na Nature em 2011 informou: "muitos aceitam a ideia de que certas características autistas- dificuldades sociais, limitação de interesse, problemas de comunicação - formam um continuunna população em geral, com o autismo extremo" (GRANDIN; PANEK, 2015, p. 14).

Desse modo, a partir da inclusão da síndrome de Asperger no DSW-IV em 1994, a criança não precisa necessariamente ser diagnosticada como "autista" para figurar no grupo do "espectro". Tal fato nos remete aos "rótulos", pois quando falamos em transtorno do espectro autista na maioria das vezes, principalmente na escola, as crianças são, em sua maioria, quase que imediatamente, rotuladas como autistas. Ainda sobre as características Gikovate (apud SANTOS, 2013, p. 25) nos diz que:

Hoje se considera que as características do autismo podem surgir desde os primeiros meses de vida ou após um período de desenvolvimento em geral após 15 meses de vida (porém, com o início dos sintomas antes de 36 meses). Este é o segundo quadro, no qual houve um período de desenvolvimento aparentemente normal, é denominado autismo regressivo e corresponde a 30\% do total de casos. Nos outros $70 \%$ não se evidencia uma regressão e os 16 sintomas estariam presentes desde o nascimento, mesmo que tais sintomas só fossem notados como problema após uma determinada idade.

A Lei $\mathrm{n}^{\circ}$ 12.764 Art. 1 inciso $1^{\circ}$ (BRASIL, 2012) considera com Transtorno do Espectro Autista (TEA) a pessoa que apresenta as seguintes características:

$\S 1$ 1o Para os efeitos desta Lei, é considerada pessoa com transtorno do espectro autista aquela portadora de síndrome clínica caracterizada na forma dos 
seguintes incisos I ou II: I - deficiência persistente e clinicamente significativa da comunicação e da interação sociais, manifestada por deficiência marcada de comunicação verbal e não verbal usada para interação social; ausência de reciprocidade social; falência em desenvolver e manter relações apropriadas ao seu nível de desenvolvimento; II - padrões restritivos e repetitivos de comportamentos, interesses e atividades, manifestados por comportamentos motores ou verbais estereotipados ou por comportamentos sensoriais incomuns; excessiva aderência a rotinas e padrões de comportamento ritualizados; interesses restritos e fixos (BRASIL, 2012).

O autismo é hoje considerado como uma síndrome comportamental com etiologias múltiplas em consequência de um distúrbio de desenvolvimento. Caracteriza-se, portanto, por um déficit na interação social visualizado pela inabilidade em relacionar-se com o outro, usualmente combinado com déficits de linguagem e alterações de comportamento (ASSUMPÇÃO JR., 2005, p. 16).

O autismo ainda que seja visto como um distúrbio de desenvolvimento, Gauderer (1993) fala que $75 \%$ das pessoas com autismo tem algum tipo de deficiência intelectual. Para Grandin e Scariano (1999, p.18) o autismo pode ser visto como:

Uma deficiência nos sistemas que processam a informação sensorial recebida fazendo a criança reagir a alguns estímulos de maneira excessiva, enquanto a outros reage debilmente. Muitas vezes, a criança se "ausenta" do ambiente que a cerca e das pessoas circunstantes a fim de bloquear os estímulos externos que lhe parecem avassaladores. O autismo é uma anomalia da infância que isola a criança de relações interpessoais. Ela deixa de explorar o mundo à sua volta, permanecendo em vez disso em seu universo interior.

A Associação Americana de Psiquiatria (APA apud ARAÚJO; LOTUFO NETO, 2014), no manual intitulado DSM-5, classifica o transtorno do espectro do autismo (TEA) entre os chamados transtornos do neurodesenvolvimento. O TEA, nesses termos, "é definido como um transtorno do desenvolvimento neurológico e global, que deve estar presente desde a infância, apresentando importantes déficits nas dimensões sociocomunicativas e comportamentais" (NUNES; AZEVEDO; SCHMIDT, 2013, p. 558).

Segundo Schwartzman (2011), “as características básicas do TEA são entendidas como déficits qualitativos e quantitativos, que embora muito abrangentes, afetam de forma mais evidente as áreas de interação social, da comunicação e do comportamento". Porém, quando nós falamos em autismo, estamos nos referindo a pessoas com habilidades absolutamente reveladoras, que calam fundo na nossa alma, e nos fazem refletir sobre quem de fato vive alienado (SILVA; GAIATO; REVELES, 2012). Sobre isso, considera-se importante destacar que 
[...] Existe um comprometimento precoce que afeta o desenvolvimento como um processo e, consequentemente, a personalidade (por meio da interação entre $o$ self $\mathrm{e}$ as experiências como o ambiente, que possibilita o desenvolvimento das noções de si, do outro e do mundo ao seu redor), seja a síndrome do autismo classificada como psicose ou como transtorno desenvolvimento. $\mathrm{Na}$ verdade, existe a falta de um modelo teórico suficientemente abrangente para dar conta das diferenças entre duas formas de classificação. [...] O que vale a pena ressaltar é que seja qual for o sistema de classificação ou a abordagem teórica adotada, a noção de que crianças com autismo apresentam déficits no relacionamento interpessoal, na linguagem / comunicação, na capacidade simbólica e, ainda, comportamento estereotipado (atentando-se para as diferenças individuais), não tem sido desafiada (BOSA, 2002, p.30)

O Autismo não tem cura, e por isso a família desempenha papel fundamental para que seu filho possa ter uma boa qualidade de vida e um bom desenvolvimento. Nesse contexto, temse que são os pais os verdadeiros especialistas no que diz respeito ao desenvolvimento da criança, afinal,

[...] Ninguém conhece seu filho melhor do que você. Se suspeitar que haja algo errado, talvez tenha razão. Em geral, a dificuldade é entender qual é o problema, sua gravidade e com quem compartilha as preocupações. A princípio, muitos de nós discutimos essas ansiedades com a família e amigos e depois consultamos um profissional da área da saúde (por exemplo, médico ou outro profissional qualificado) se ainda estivermos preocupados. $\mathrm{Na}$ maioria das vezes, ficamos mais tranquilos e, rápida ou gradualmente, os comportamentos que nos preocupam desaparecem. Ocasionalmente, contudo, o comportamento da criança e as preocupações dos pais persistem. Se for esse o caso, é preciso consultar novamente um profissional da saúde (WILLIAMS, 2008, p. 3).

No entanto, deve-se levar em consideração que as características de uma criança com autismo muitas vezes se confundem. Por isso é de extrema importância que se faça um acompanhamento profissional, para que se chegue a um diagnóstico preciso. Muitas vezes, a falta de um acompanhamento específico para essas crianças acaba por criar dificuldades cotidianas, não apenas no espaço de suas casas, mas afeta também sua rotina nos espaços educacionais. A necessidade do acompanhamento especializado se coloca na medida em que o autista necessita um olhar diferenciado, uma abordagem educativa direcionada e intencional, afinal, os autistas apresentam várias alterações neurológicas, fato que explica, em parte, sua maneira própria de ver o mundo e interagir com ele.

\section{TRANSTORNO DO ESPECTRO AUTISTA X EDUCAÇÃO INCLUSIVA}

A criança com Transtorno do Espectro Autista possui uma percepção diferenciada do mundo. Seu modo de ver e interagir com as pessoas e com o contexto é diferenciada, e, muito 
embora as características que definem o autismo sejam bastante abrangentes, estas acabam por afetar as crianças/o indivíduo, nos campos da interação social e da comunicação. Desse modo, aos educadores, cabe compreender que a escola pode ser um dos espaços que favorecem o desenvolvimento infantil, ou seja, como um espaço no qual há a oportunidade de convivência entre crianças e adultos.

Embora as crianças com transtorno do espectro autista apresentem dificuldades em estabelecer relações sociais, bem como com a comunicação interpessoal, há pesquisas que consideram a importância da interação social para o seu desenvolvimento, desde que levadas em consideração as suas características individuais. Desse modo,

[...] entende-se que as áreas de interação social, comunicação e comportamento se articulam intimamente no desenvolvimento humano desde a mais tenra idade. Considerando que os indivíduos com autismo apresentam prejuízos nessas áreas, cabe aos profissionais, que com eles trabalham, utilizarem estratégias que contemplem a aquisição de habilidades que são prérequisitos para que outras se efetivem. (LEMOS; SALOMÃO; AGRIPINORAMOS, 2014, p. 118)

Ainda Lemos, Salomão e Agripino-Ramos (2014) destacam que a escola pode ser um espaço importante no que diz respeito ao desenvolvimento infantil, não apenas pela oportunidade de interação e convivência do autista com outras crianças, mas também pelo papel do professor. Assim sendo,

[...] aproveitar a atenção e a iniciativa de crianças com autismo para explorar determinados objetos e utilizar esta iniciativa como via para estabelecer e manter as trocas de ações com essas crianças pode ser uma alternativa frutífera para enriquecer o contato social delas com outras pessoas (LEMOS; SALOMÃO; AGRIPINO-RAMOS, 2014, p. 122).

Nesse sentido, o professor pode e dever ser responsável pelas mediações, que favorecem a aprendizagem e a aquisição de diferentes habilidades pelas crianças. Sobre isso, Kupfer e Petri (2000, p. 116), sobre isso, afirmam que

As crianças autistas possuem ilhas de inteligência preservadas, que podem desaparecer caso não as ajudemos a lhes dar sentido. Podem por falta de sentido, direção, porque não são utilizadas para alcançá-las no outro, desaparecer, ou se transformar em estereotipias. Assim, a frequência à escola acaba sendo um instrumento crucial, se não de crescimento, ao menos de conservação das capacidades já adquiridas.

Michelle Dawson (apud GRANDIN; PANEK, 2015), pesquisadora do Transtorno do Espectro Autista percebeu vários pontos fortes, manifestados em crianças com TEA do que em 
crianças sem o Transtorno do Espectro Autista, em testes de inteligência realizados no ano de 2007. Testes como escala Wechsler de inteligência para as crianças, e as matrizes Progressivas de Raven. A aplicação de tais testes em crianças autistas apresentou resultados interessantes:

Dawson descobriu que a medida da inteligência na população autista depende do tipo de teste. No teste Wechsler, um terço dos indivíduos com autismo foi classificado como "de baixo funcionamento". No teste Raven, porém, isso só ocorreu com 5\% - e um terço foi classificado como de "alta inteligência". No teste Wechsler, os indivíduos autistas em seu conjunto pontuaram muito abaixo da população média, ao passo que no teste Raven pontuaram na faixa normal (GRANDIN; PANEK, 2015, p. 130).

A partir do que pontuam tais pesquisas, nos é possível perceber que a criança com TEA tem um grande potencial intelectual. O desenvolvimento de suas potencialidades, entretanto, depende da abordagem utilizada pelo professor. Sobre isto, Lemos et al (2016) enfatizam que os professores, por serem os profissionais que lidam diretamente com os alunos, são, entre os atores emocionais, os mais eficazes no processo de inclusão. Desse modo, o sucesso (ou fracasso) do processo de aprendizagem da criança autista pode ser visto como reflexo da intervenção pedagógica. Assim sendo, não é possível menosprezar, nesse processo, a necessidade que o professor possui em conhecer especificidades inerentes ao Transtorno do Espectro Autista, além de sua experiência, formação, crenças e características pessoais.

Outros aspectos relevantes para a inclusão da criança com TEA na escola, é a participação das famílias nesse processo. Entretanto, muitas vezes os pais de uma criança diagnosticada autista sentem grande insegurança em relação ao seu desenvolvimento, bem como em relação ao processo de inclusão escolar. No entanto, conforme destacam Panerai et al. (2009), o papel dos pais no processo educativo tem fundamental importância, uma vez que estes são capazes de promover muitos aspectos positivos em relação à aprendizagem e ao desenvolvimento de seus filhos.

No processo educativo, é importante que tanto pais quanto professores tenham em mente que toda mudança na a rotina de uma criança autista causa resistência. Nesse contexto, levando em consideração que a rotina escolar é muito dinâmica, fato que pode causar reações desagradáveis na criança. Segundo Belizário e Cunha (2010) essas reações são comuns, uma vez que a sua entrada na escola e as vivências iniciais nesse espaço representam algo novo em sua rotina já instituída.

A escola, naquele momento, é uma experiência desconhecida e de difícil apropriação de sentido e propósito pela criança. Por parte dos professores, a vivência desses primeiros momentos pode ser paralisante, carregada de sentimento de impotência, angústia e geradora de falsas convicções a respeito 
da impossibilidade de que a escola e o saber/fazer dos professores possam contribuir para o desenvolvimento daquela criança. Mediante as dificuldades iniciais, as escolas recorrem a todo tipo de tentativa de acolhimento ao aluno. Essa é uma atitude absolutamente compreensível, embora sejam importantes alguns cuidados (BELIZÁRIO; CUNHA, 2010, p. 22).

Desse modo, o conhecimento do professor acerca das necessidades de seus alunos tem papel fundamental nesse processo, de modo que esse profissional possa procurar abordagens que facilitem o processo de inclusão, aprendizagem e desenvolvimento, uma vez que a identificação do que se deve ensinar a uma criança autista, e como fazê-lo, passam a ser fundamentais. Assim sendo, faz-se preciso levar em consideração as diferenças entre os alunos e suas particularidades, podendo ser realizadas adaptações de acordo com a realidade de cada criança autista e suas especificidades, conforme lembram Borges e Probst (2015).

Nesse contexto, Vygotsky (1978 apud SANTOS, 2013) nos permitem saber que o docente, na medida em que atua como mediador no processo de desenvolvimento e aprendizagem infantil, deve proporcionar atividades que as estimulem a conhecer e a desenvolver novas habilidades, atuando desta forma na Zona de Desenvolvimento Proximal (ZDP). Assim sendo, o professor deve ter consciência de que

[...] cada criança dentro de sala de aula se desenvolve, amadurece e aprende de forma particular, ou seja, atinge expectativas de aprendizagens únicas e que a todo tempo deve ser valorizada e estimulada a atingir níveis cada vez mais elevados (VYGOTSKY, 1978 apud SANTOS, 2013, p.13).

Os professores podem e devem auxiliar as crianças autistas a desenvolverem seus talentos, pois, conforme destaca Grandin (2011), em alguns casos, crianças autistas de apenas sete anos de idade já sabem desenhar com perspectiva tridimensional. No entanto, para que esse processo educacional se efetive, o primeiro passo é permitir que a criança autista comece a perceber esse mundo à sua volta, que conheça o espaço escolar e que permita começar a socializar.

Quando a aprovação pela rotina escolar demora em acontecer, faz-se preciso um olhar cauteloso para com essa criança, e exercícios simples auxiliam o professor nesse momento, por exemplo, toda vez que a turma sair da sala ou trocar o que está fazendo é importante explicar para essa criança autista o que vem a seguir, o começo é difícil, mas podemos obter resultados excelentes se apenas mudarmos as abordagens para melhor atender a essa criança.

Ademais, considera-se que o sucesso desse processo esteja relacionado ao papel do professor e dos pais, principalmente a partir do reconhecimento da criança autista como uma pessoa, um ser humano pleno, porém em seu modo singular. Essa criança possui condições de 
desenvolvimento e aprendizagem, bem como de produção cultural, porém estas ocorrem ao seu modo, de forma particular. Assim sendo, os pais e professores devem ser "promotores das melhores condições possíveis para a expressão de suas potencialidades, para a manifestação de seu mundo mental, para suas ações, suas interações, sua exploração do mundo e de si mesmos", conforme assevera Ávila (2000, p. 19).

\section{ALGUNS (POSSÍVEIS) ASPECTOS CONCLUSIVOS}

Levando em consideração que o presente estudo teve como objetivo refletir sobre os processos educativos e particularidades das crianças com Transtorno do Espectro Autista, percebeu-se que o autismo infantil vem sendo estudados por vários autores, que buscam compreender melhor esse transtorno de desenvolvimento, dando base à reflexões e colaborando o desenvolvimento de propostas educacionais inclusivas que atendam adequadamente esse público.

A partir da realização do estudo nos é possível concluir que as pessoas que têm o Transtorno do Espectro Autista (TEA) podem apresentar alguns sintomas entre os 12 e os 24 meses de vida, com uma variante de gravidade e intensidade, dependendo da criança, bem como que o Autismo é hoje considerado como uma síndrome comportamental com etiologias múltiplas em consequência de um distúrbio de desenvolvimento.

As características de uma criança com autismo muitas vezes se confundem, é de extrema importância que se faça um acompanhamento para que se chegue a um diagnóstico preciso, e hoje podemos perceber muitas vezes que a falta de um acompanhamento específico para essas crianças dificulta a vida delas, e também sua rotina nos espaços educacionais, porque essas crianças precisam que um olhar diferenciado para como se faz a abordagem no seu dia a dia, e é fato que a abordagem que se precisa usar para uma criança sem TEA, é diferente da que se deve usar para uma criança com o transtorno.

A criança com Transtorno do Espectro Autista é especial em todos os sentidos, pois ela tem um olhar diferenciado do mundo que a cerca, e, por isso, nos faz pensar, refletir e avaliar a forma com que colocamos em prática as nossas próprias vidas. , As crianças autistas possuem ilhas de inteligência preservadas, que podem desaparecer caso não as ajudemos a lhes dar sentido, tendo potencial incrível. Desenvolver esse potencial, entretanto, depende da abordagem pedagógica utilizada, e isso é de extrema importância quando falamos de escola e de educação inclusiva, lembrando que o acesso à escola é um direito de todos, e, por isso, é necessária a proposição de ações educativas que atendam também as pessoas com transtornos, 
déficits, síndromes ou outras deficiências, na escola regular.

Conclui-se que o desafio atual está, para além do conhecimento acerca das particularidades do autismo, nas possibilidades de inclusão educacional e social dos sujeitos com transtorno do espectro autista, de modo que essa inclusão não preveja apenas a presença dos alunos autistas em meio aos demais alunos, mas a sua participação ativa no seu processo de desenvolvimento, aprendizagem e socialização.

\section{REFERÊNCIAS}

ARAÚJO, Álvaro Cabral; LOTUFO NETO, Francisco. A Nova Classificação Americana Para os Transtornos Mentais - o DSM-5. Revista. Brasileira de Terapia Comportamental e Cognitiva. V. XVI, no. 1, p.76-82, 2014. Disponível em:

<http://pepsic.bvsalud.org/pdf/rbtcc/v16n1/v16n1a07.pdf>. Acesso em 08 abr. 2017.

ASSUMPÇÃO JR., Francisco B. Diagnóstico diferencial dos transtornos abrangentes de desenvolvimento. In: CAMARGOS JR., Walter et al. (Orgs.). Transtornos invasivos do desenvolvimento. 2 ed. Brasília: Secretaria Especial dos Direitos Humanos; Coordenadoria Nacional para Integração da Pessoa Portadora de Deficiência, 2005.

ÁVILA, Laszlo A. Psicanálise, educação e autismo: encontro de três impossíveis. Revista. Latinoamericana de Psicopatia Fundamental. São Paulo, v. 3, n. 1. Disponível em: <http://www.scielo.br/pdf/rlpf/v3n1/1415-4714-rlpf-3-1-0011.pdf>. Acesso em 17 ago. 2017.

BOSA, Cleonice. Autismo: atuais interpretações para antigas observações. In: BAPTISTA, Cláudio Roberto et al. Autismo e educação: reflexões e propostas de intervenção. Porto Alegre: Artmed, 2002.

BELISÁRIO JÚNIOR, José Ferreira; CUNHA Patrícia. A educação especial na perspectiva da inclusão escolar: transtornos globais do desenvolvimento. Brasília: Ministério da Educação, Secretaria de Educação Especial; Fortaleza: Universidade Federal do Ceará, 2010. v. 9.

BORGES, Rosicléia Melori Ribeiro; PROBST, Melissa. Transtorno do espectro autista (tea) e as artes: o ensino da arte no universo autista. Revista de Educação Dom Alberto. Santa Cruz do Sul, n. 7, v. 1, p. 46-66, jan./jul. 2015. Disponível em: <http://www.domalberto.edu.br/wpcontent/uploads/2017/05/Transtorno-do-Espectro-Autista-TEA-e-as-Artes-O-Ensino-da-Arteno-Universo-Autista.pdf>. Acesso em 4 dez. 2017.

BRASIL, MINISTÉRIO DA SAÚDE. Linha de cuidado para a atenção integral ás pessoas com transtorno do espectro do autismo e suas famílias no sistema único de saúde: Série A. Normas e Manuais Técnicos. Brasília: Ministério da Saúde, 2013.

BRASIL. Lei $n^{\circ}$ 12.764, de 27 de dezembro de 2012. Disponível em: <http://www.planalto.gov.br/ccivil_03/_ato2011-2014/2012/lei/112764.htm>. Acesso em 18 maio 2017.

COUTINHO, Ana Flávia de Oliveira. Interação Mãe-Criança Autista em situação de 
brincadeira livre e computador. 2012. Tese (Doutorado em Psicologia Social) - Universidade Federal da Paraíba, João Pessoa, 2012.

DOWN. Movimento-Observatório de Favelas do Rio de Janeiro. Escola para todos. Educação Inclusiva: O que os pais sabem? Federação Brasileira das Associações de Síndrome de Down (FBASD). Brasil, 2014.

GAUDERER. Ernst Christian. Autismo. São Paulo: Atheneu, 1993.

GIL, Antonio Carlos. Métodos e técnicas de pesquisa social. 6 ed. São Paulo: Atlas, 2008.

GOMES, Camila Graciella Santos. Desempenhos emergentes na aquisição de leitura funcional de crianças com transtorno do espectro autístico. Dissertação (Mestrado em Educação Especial) - Universidade Federal de São Carlos. São Carlos, SP, 2007. Disponível em: 〈https://repositorio.ufscar.br/bitstream/handle/ufscar/2975/1674.pdf?sequence=1 >. Acesso em 10 de jun. 2017.

GRANDIN, Temple; PANEK, Richard. O cérebro autista. Rio de Janeiro: Record, 2015.

GRANDIN, Temple; SCARIANO, Margareth M. Uma menina estranha: autobiografia de uma autista . São Paulo: Cia das letras, 1999.

GRANDIN, Temple. Mistérios de uma mente autista. Joinville: Clube de Autores Publicações, 2011.

KUPFER, Maria Cristina. M; PETRI, Renata. Por que ensinar a quem não aprende? Estilos da Clínica. São Paulo, vol.5, n.9, 2000. Disponível em:

<http://pepsic.bvsalud.org/pdf/estic/v5n9/_08.pdf> Acesso em 15 abr. 2017.

LEMOS Emellyne Lima de Medeiros Dias; SALOMÃO Nádia Maria Ribeiro; AGRIPINORAMOS, Cibele Shírley. Inclusão de crianças autistas: um estudo sobre interações sociais no contexto escolar. Revista Brasileira de Educação Especial. Marília, v. 20, n. 1, p. 117-130, jan-mar, 2014. Disponível em: 〈http://www.scielo.br/pdf/rbee/v20n1/a09v20n1.pdf>. Acesso em 15 ago. 2017.

LEMOS, Emellyne Lima de Medeiros Dias et al. Concepções de pais e professores sobre a inclusão de crianças autistas. Fractal: Revista de Psicologia, v. 28, n. 3, p. 351-361, set.-dez. 2016. Disponível em: <http://www.scielo.br/pdf/fractal/v28n3/1984-0292-fractal-28-0300351.pdf $>$. Acesso em 20 out. 2017.

NUNES, Debora Regina de Paula; AZEVEDO, Mariana Queiroz Orrico; SCHMIDT, Carlo. Inclusão educacional de pessoas com autismo no Brasil: uma revisão da literatura. Revista Educação Especial. Santa Maria, v. 26, n. 47, p. 557-72, set./dez. 2013. Disponível em <https://periodicos.ufsm.br/educacaoespecial/article/view/10178/pdf>. Acesso em: 17 mar. 2017.

PANERAI, Simonetta et al. Special education versus inclusive education: the role of the TEACCH Program. Journal Autism Dev. Disord., n. 29, p. 874-882, 2009. Disponível em: $<$ http://imap.interactingwithautism.com/pdf/treating/185.Special\%20Education $\% 20$ Verssus $\%$ 20Inclusive.TEACCH.pdf $>$. Acesso em 14 set. 2017. 
SANTOS, Neide Pereira. O desenvolvimento intelectual da criança com autismo e o método TEACCH. 2013. Trabalho de Conclusão de Curso (Licenciatura em Pedagogia) - Faculdade Método de São Paulo, 2013.

SCHWARTZMAN, José Salomão. Transtorno do espectro do autismo: conceitos e generalidades. In: SCHWARTZMAN, José Salomão; ARAÚJO, Ceres Alves de. Transtornos do espectro do autismo. São Paulo: Memnon, 2011.

SILVA, Ana Beatriz Barbosa; GAIATO, Mayara Bonifácio; REVELES Leandro Thadeu. Mundo Singular. Rio de Janeiro: Objetiva, 2012.

TAMANAHA, Ana Carina; PERISSINOTO, Jacy; CHIARI, Brasília Maria. Uma breve revisão histórica sobre a construção dos conceitos do Autismo Infantil e da síndrome de Asperger. Revista da Sociedade Brasileira de Fonoaudiologia, v.13, n.3, São Paulo, p. 296299, 2008. Disponível em:<http://www.scielo.br/pdf/rsbf/v13n3/a15v13n3.pdf >.Acesso em: $17 / 05 / 2017$.

WILLIAMS, Chris. Convivendo com autismo e síndrome de asperger: estratégias práticas para pais e profissionais. São Paulo: Mbooks, 2008.

\section{SOBRE AS AUTORAS}

Hélen Bandeira Rosso Matias é graduada em Pedagogia e especialista em Educação Especial Inclusiva pelo Centro Universitário Leonardo da Vinci (UNIASSELVI).

E-mail: helenrosso.matias@gmail.com

Melissa Probst é Doutora em Educação pela Universidade Tuiuti do Paraná (UTP) e Mestre em Educação pela Universidade Regional de Blumenau (FURB). Professora do Instituto Federal Catarinense (IFC - campus Araguari) e da Universidade Regional de Blumenau. Integrante do Grupo de Pesquisa Saberes de Si e Vozes Livres da Universidade Regional de Blumenau (FURB).

E-mail: mel.probst@gmail.com 